\title{
Mirizzi syndrome mimicking cholangiocarcinoma. Case report
}

\author{
Gabriel Lorente Mitsumoto, ${ }^{1}$ Lucas Augusto Monetta da Silva, ${ }^{1}$ Mauricio Alves Ribeiro, ${ }^{2}$ \\ Mariana Martins Tocchio, ${ }^{1}$ Nátalie Emy Yvamoto, ${ }^{1}$ Talita Di Santi, ${ }^{1}$ Caroline Petersen da \\ Costa Ferreira, ${ }^{3}$ Luiz Arnaldo Szutan ${ }^{2}$
}

\author{
${ }^{1}$ School of Medicine, Santa Casa de Sao Paulo School of Medical Sciences. \\ ${ }^{2}$ Department of Surgery, Liver and Portal Hypertension Group, Santa Casa de Sao Paulo School of Medical Sciences. \\ ${ }^{3}$ Postgraduate from Santa Casa de Sao Paulo School of Medical Science. \\ Sao Paulo, SP - Brasil.
}

Acta Gastroenterol Latinoam 2020;50(2):198-204

Recibido: 06/02/2019 / Aceptado: 29/10/2019 / Publicado online: 29/06/2020

\section{Summary}

Mirizzi syndrome (MS) is a rare condition whose clinical presentation is unspecific, with obstructive jaundice being the most common form. MS is often not recognized at initial presentation, which can result in morbidity and biliary injury. Preoperative diagnosis is uncommon and over 50\% of patients with MS are diagnosed during surgery. There are no clinical features to distinguish MS from cholangiocarcinoma, except that patients with cholangiocarcinoma are on average ten years older than patients with MS. We report the case of a 51-year-old female patient who presented with jaundice and weight loss. Following investigation with laboratory and imaging exams, the initial diagnosis was Bismuth II cholangiocarcinoma. The patient underwent surgical intervention, and anatomopathological examination of the specimen showed the correct diagnosis to be MS. Despite the rarity of its incidence, physicians must keep MS in mind as

Correspondencia: Mauricio Alves Ribeiro

Rua Mato Grosso, 306 conj. 1311 - CEP 01239040 São Paulo, SP - Brazil Tel.: 551199631237

Correo electrónico: mauricio.ribeiro@me.com a possible differential diagnosis for cholangiocarcinoma and vice-versa. We discuss this case in the context of a brief review of the literature on Mirizzi syndrome mimicking cholangiocarcinoma.

Key words. Mirizzi syndrome, cholangiocarcinoma, gallstones, biliary tract diseases, biliary obstruction, Rouxen-Y hepaticojejunostomy.

\section{Síndrome de Mirizzi que simula colan- giocarcinoma. Reporte de caso}

\section{Resumen}

El sindrome de Mirizzi (SM) es una enfermedad rara cuya presentación clínica no es específica, siendo la forma más común la ictericia obstructiva. El SM a menudo no se reconoce en la presentación inicial, lo que puede resultar en morbilidad $y$ lesiones biliares. El diagnóstico preoperatorio no es frecuente y más del $50 \%$ de los pacientes con SM se diagnostican durante la cirugía. No hay caracteristicas clínicas para distinguir SM del colangiocarcinoma, excepto que los pacientes con colangiocarcinoma son en promedio diez años mayores que los pacientes con SM. Presentamos el caso de una paciente de 51 años que consultó por ictericia y pérdida de peso. Tras la investigación con exámenes de laboratorio e imágenes, el diagnóstico inicial fue un colangiocarcinoma de Bismuth II. La paciente se sometió a una intervención quirúrgica, y el examen anatomopatológico de la pieza quirúrgica determinó que el diagnóstico correcto era SM. A pesar de la rareza de su incidencia, los médicos deben tener en cuenta el SM como posible 
diagnóstico diferencial con el colangiocarcinoma y viceversa. Discutimos este caso en el contexto de una breve revisión de la literatura sobre el SM que simula un colangiocarcinoma.

Palabras claves. Sindrome de Mirizzi, colangiocarcinoma, cálculos biliares, enfermedades del tracto biliar, obstrucción biliar, hepaticojejunostomía Roux-en-Y.

\section{Abbreviations}

MS: Mirizzi syndrome.

ERCP: Endoscopic retrograde cholangiopancreatography.

CT: Computed tomography.

\section{Introduction}

Mirizzi syndrome (MS) was firstly described by Kehr, ${ }^{1}$ and Ruge, ${ }^{2}$ in the early 1900s, but it was only in 1948 that Pablo Mirizzi ${ }^{3}$ fully described this disorder and ultimately provided a name for this uncommon complication of long-standing gallstone disease. MS is a rare condition, with an incidence in patients undergoing biliary surgery varying from 0.7 to $1.4 \%,{ }^{4}$ and is characterized by an acute or chronic inflammatory condition secondary to a single large stone or multiple small gallstones impacted in Hartmann's pouch or in the gallbladder infundibulum and cystic duct, causing mechanical obstruction of the common hepatic duct., 6

The age of MS patients ranges from 53 to 70 years of age with around $70 \%$ of cases being in females. Nonetheless, it may occur at any age and in any patient with gallstones..$^{5-7}$ The clinical presentation of MS is unspecific with obstructive jaundice (60-100\%) accompanied by abdominal pain over the right upper abdominal quadrant $(50-100 \%)$ and fever in the context of a patient with known or suspected gallstone disease being the most commonly presented profile. ${ }^{4-6}$ Frequently, patients with MS present in the setting of acute cholecystitis, acute cholangitis or acute pancreatitis. ${ }^{4-7}$ The most common laboratory finding in these patients is hyperbilirubinemia, although high levels of the malignancy marker CA19-9 have also been found in patients with MS..$^{8-11}$ The diagnosis of MS is based on the clinical characteristics described and a high index of suspicion or surgical intuition, which may be complemented by radiological images and endoscopic procedures, such as ultrasonography, computed tomography (CT), magnetic resonance (MRCP), endoscopic retrograde cholangiopancreatography (ERCP) and endoscopic ultrasound. ${ }^{6} \mathrm{MS}$ is often not recognized at initial presentation, which can result in morbidity and biliary injury. ${ }^{12}$

The accurate diagnosis of MS is of particular impor- tance to surgeons as the condition may be confused with choledocholithiasis, bile duct stricture or cholangiocarcinoma on initial presentation and hence inappropriate surgical treatment associated with a significantly increased risk of inadvertent bile duct injury. ${ }^{13,14}$ Due to the high levels of CA19-9, the results must be interpreted cautiously in patients with suspected biliary malignancy, because if MS is not ruled out, the patient would be incorrectly labeled as having biliary tract or gallbladder cancer and could miss the opportunity for curative surgery. ${ }^{6}$

The objective of this study was to undertake a brief review of the literature and to report a case of a patient with MS which was thought to be cholangiocarcinoma, with a correct diagnosis only being made after surgery by anatomopathological examination.

\section{Case report}

We present the case of a 51-year-old woman who presented at the out-patient department complaining of jaundice alongside a weight loss of $6 \mathrm{~kg}$ over the previous two weeks. On examination she had no other symptoms, besides jaundice.

A gallbladder ultrasound showed multiple echogenic foci in the gallbladder consistent with cholelithiasis and intrahepatic biliary channel and choledochal duct dilation. An ERCP did not show an obvious common bile duct stone but did show a stricture in the common hepatic duct suggestive of cholangiocarcinoma (Figure 1).

Figure 1. ERCP without obvious common bile duct stone but with a stricture in the common hepatic duct.

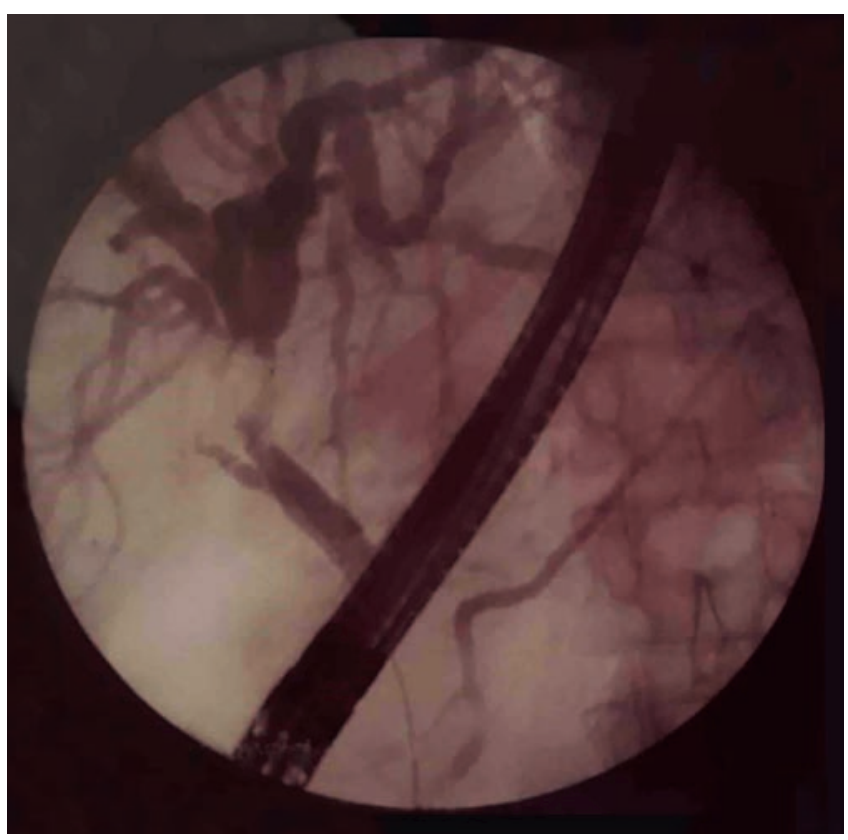


A stent was inserted in the biliary tract. An abdominal computed tomography (CT) scan revealed intrahepatic biliary ducts dilation, a hypodense gallbladder with parietal calcifications that may correspond to porcelain gallbladder sug- gestive of cholangiocarcinoma. (Figure 2 A-E).

The patient was therefore placed on the list for the surgical intervention 1 month after her initial presentation of symptoms and Bismuth type II cholangiocarcinoma diagnosis.

Figure 2. A) Computed tomography showing the prosthesis in the intra-hepatic biliary tract. B) Computed tomography showing the prosthesis exteriorization via the duodenal papilla. $C-E$ ) Computed tomography of a coronal section showing the prosthesis placed in the biliary tract during ERCP.
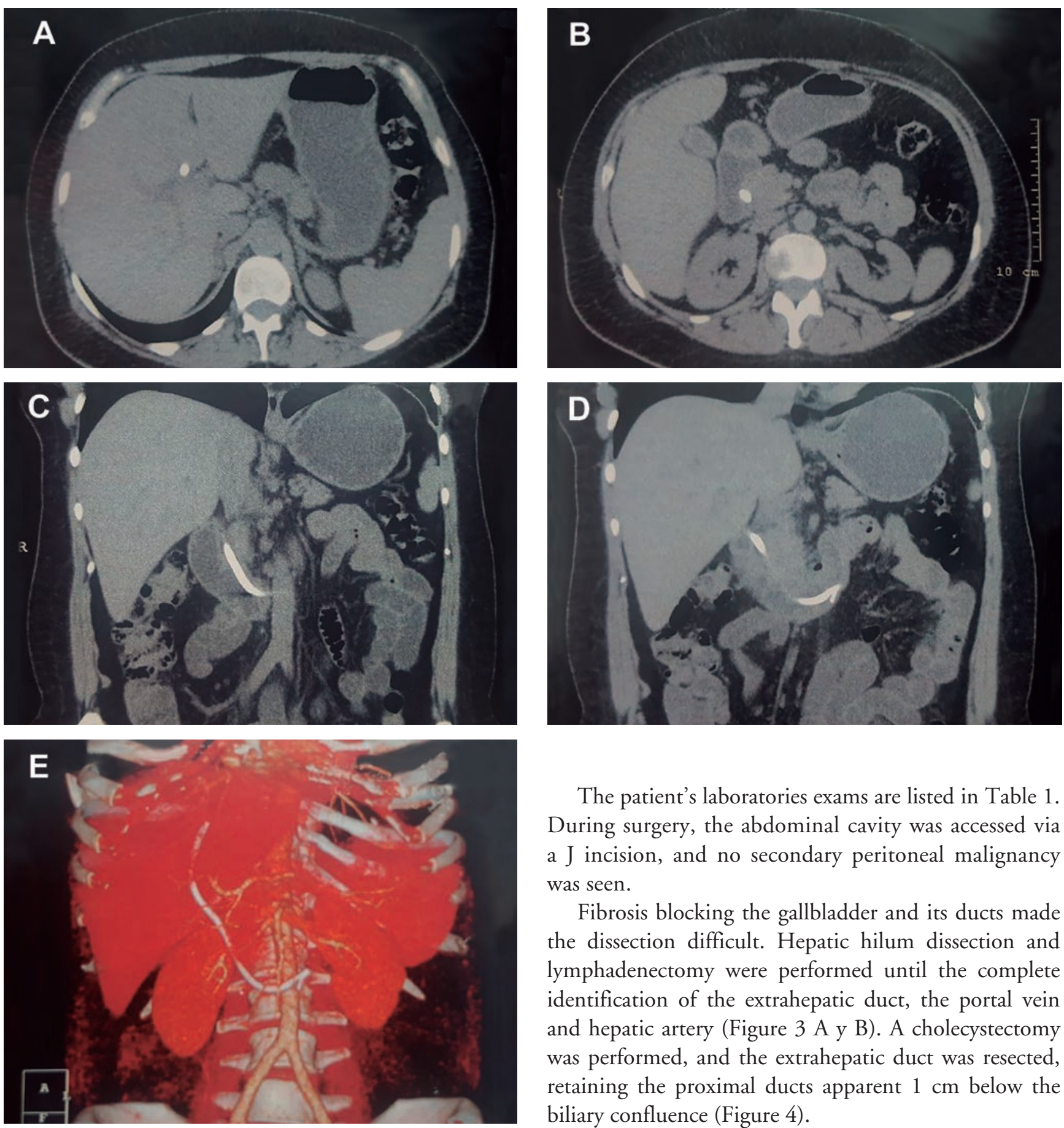

The patient's laboratories exams are listed in Table 1. During surgery, the abdominal cavity was accessed via a $\mathrm{J}$ incision, and no secondary peritoneal malignancy was seen.

Fibrosis blocking the gallbladder and its ducts made the dissection difficult. Hepatic hilum dissection and lymphadenectomy were performed until the complete identification of the extrahepatic duct, the portal vein and hepatic artery (Figure 3 A y B). A cholecystectomy was performed, and the extrahepatic duct was resected, retaining the proximal ducts apparent $1 \mathrm{~cm}$ below the biliary confluence (Figure 4). 
Table 1. Laboratory exams.

10 days before admittance

Hemoglobin level

Total bilirubin

Direct bilirubin

Alkaline phosphatase

GGT
12.7

7.5

5.8

196

1398
Admittance

11.4

3.9

1.0

453

1240
Reference values ${ }^{27}$

$13.5-17.5$

0.20 to $1.20 \mathrm{mg} / \mathrm{dL}$

$1.0 \mathrm{mg} / \mathrm{dL}$

40 to $129 \mathrm{U} / \mathrm{L}$

12 to $73 \mathrm{U} / \mathrm{L}$

Figure 3. A) Intraoperative view showing hepatic artery, common hepatic duct, portal vein and gallbladder. B) Intraoperative view showing hepatic artery, common hepatic duct and portal vein.
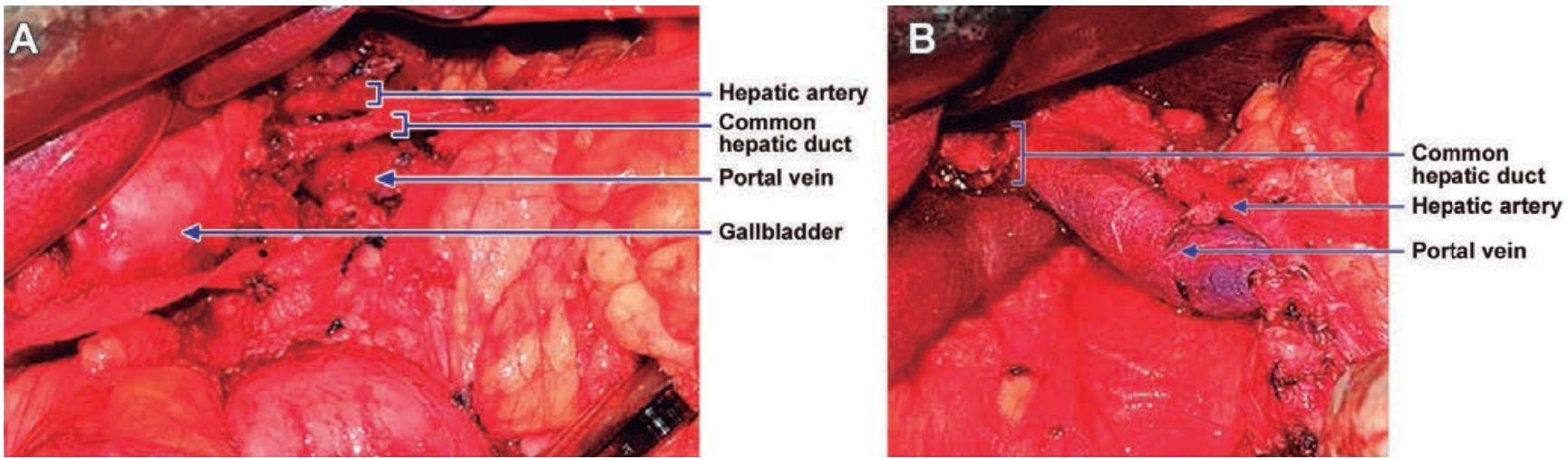

Figure 4. Gallbladder open to the biliary duct.

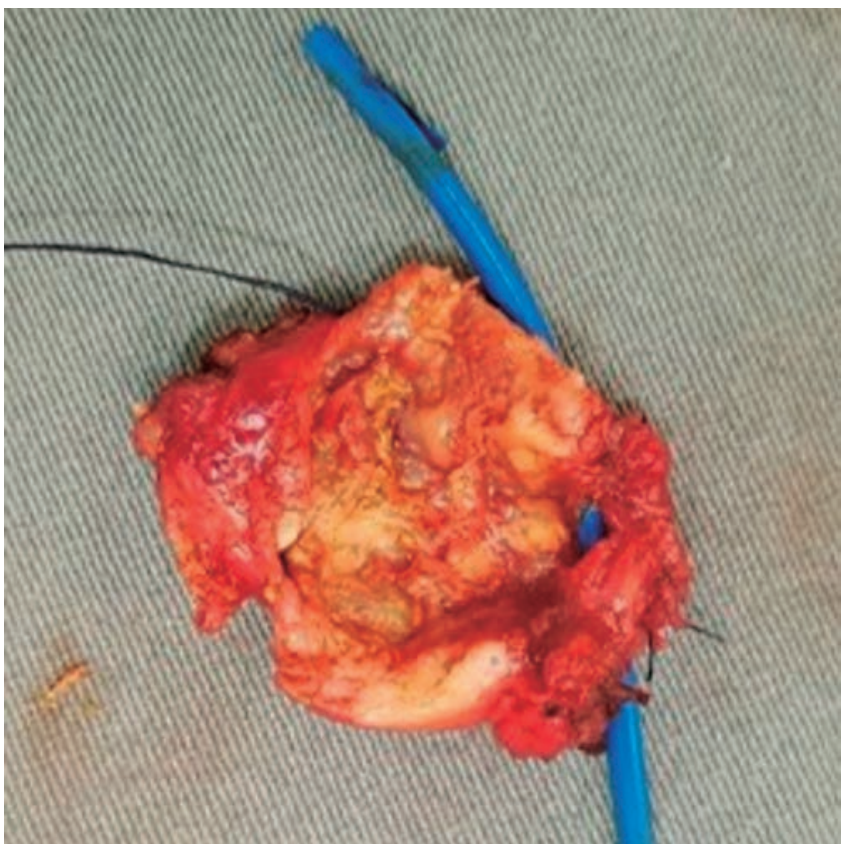

During the operation, frozen section biopsy showed no signs of malignancy at the proximal and distal ducts, only chronic inflammation. The material resected were sent for anatomopathological examination. Roux-en-Y hepaticojejunostomy was performed.

The patient had an uneventful postoperative recovery period and was discharged from hospital. The anatomopathological examination of the specimen collected during surgery confirmed the correct diagnosis of MS.

\section{Discussion}

This case report is a rare case of Mirizzi syndrome diagnosed postoperatively, appearing as cholangiocarcino$\mathrm{ma}$ in the preoperative imaging exams.

The rates of Mirizzi syndrome among patients with symptomatic cholelithiasis are $1-2 \%$ according to some studies. ${ }^{4,6}$ However, in low- and middle-income countries, particularly in Latin America, MS is a more common condition with a reported incidence ranging from 4.7-5.7\%.6.7 A long cystic duct, a cystic duct parallel to 
the bile duct, and a low insertion of the cystic duct into the bile duct, have been regarded as predisposing factors for the development of MS. ${ }^{6}$ In this case, the patient presented symptoms of Bismuth type II cholangiocarcinoma, such as obstructive jaundice and weight loss.

The incidence rate of the different types of MS according to Beltrán and Csendes ${ }^{7}$ are the following: Mirizzi type I is (the most common) $10.5-78 \%$, Mirizzi II 15-41\%, Mirizzi III 3-44\%, and Mirizzi IV 1-4\%. Mirizzi $\mathrm{V}$ (which includes the presence of a cholecystoenteric fistula together with any other type of Mirizzi) can be present in up to $29 \%$ of patients.

The differential diagnosis of MS includes any other benign or malignant cause of obstructive jaundice, such as gallbladder cancer, cholangiocarcinoma, pancreatic cancer, sclerosing cholangitis, or metastatic disease. ${ }^{6,15}$

Preoperative diagnosis of MS, although ideal, it is not always possible, being reported to occur in $8-62.5 \%$ of patients. ${ }^{6}$ In intent to perform preoperative diagnosis, abdominal ultrasound is the initial exam. Computed tomography, MRCP and ERCP are complementary exams. Abdominal ultrasound, which has a sensitivity of $8.3-27 \%$, generally shows cholelithiasis with impacted gallstone in Hartmann's pouch or in the gallbladder infundibulum, contracted gallbladder and biliary ducts dilation. ${ }^{16,17}$

Abdominal CT does not have specific radiological features for MS, but this technique can be very effective in detecting the cause and location of biliary obstruction. ${ }^{18}$ It also may either exclude neoplastic lesions or suggest them in the presence of lymph node enlargement, hepatic infiltration or metastasis. ${ }^{16}$

MRCP is a valuable method to study the biliary tract, with an accuracy of 50\% for the diagnosis of MS. ${ }^{16}$ Using image weighted in T2 it is possible to differentiate between inflammatory (characteristic of MS) and neoplastic process, which may not be possible using ultrasound or CT. ${ }^{18,19}$

ERCP, modality of image exam with the most sensitivity, has an accuracy of 50-100\%, performing the diagnosis of cholecystobiliary fistula and, when associated with sphincterotomy, allows for biliary decompression and prosthesis placement in patients with obstructive jaundice and cholangitis. ${ }^{16}$ In the case reported, the patient underwent ERCP, hence a biliary tract study was already performed, thus MRCP was found unnecessary.

There are a few cases reported in the literature about using echoendoscopy/endoscopic ultrasound in the diagnosis of MS. ${ }^{20,21}$ The findings using this type of exam that suggest MS are a hypoechoic multilaminated structure with internal calcification at the cys- tic duct region. ${ }^{22}$ and common hepatic duct dilation. Goméz and Meneses, ${ }^{21}$ reported two cases of MS with the diagnosis made from echoendoscopy, proposing this exam as the gold-standard for this disease. In our view, echoendoscopy is another valuable exam, but generally the patients are admitted at the emergency department, and this is not an easily accessible exam in this context. Furthermore, echoendoscopy is usually used for staging when malignancy is suspected.

If a preoperative diagnosis is not made, intraoperative recognition and proper management is essential. Inadequate recognition of this condition leads to high preoperative morbidity and mortality. ${ }^{15}$ Our patient was a postoperative diagnosis, made through anatomopathological examination, but in the intraoperative we also had this suspicion.

Surgery is the primary treatment choice for MS. ${ }^{6,23}$ Distorted biliary anatomy with increased risk of bile duct injury poses a daunting surgical challenge, given that the correct preoperative diagnosis is uncommon, ${ }^{24}$ and over $50 \%$ of patients with MS are diagnosed during surgery. ${ }^{25}$ In patients who are not surgical candidates, endoscopic or percutaneous biliary decompression may be the initial treatment. ${ }^{23}$

There are no clinical features to distinguish MS from cholangiocarcinoma, except that patients with cholangiocarcinoma are on average ten years older than patients with MS alone. ${ }^{26}$ It must be kept in mind that high levels of CA19-9 have been found in some patients with MS..$^{8-10}$

Despite the first suspicion of cholangiocarcinoma, the profile of this case report was similar to MS. The incidence of carcinoma is highest in older patients (6070 years old), while our patient was 51 years old. MS is more prevalent in woman, as in this case. However, the clinical and imaging exams were more suggestive of carcinoma, such as a consumptive syndrome or porcelain gallbladder at CT.

For the literature review we searched the PubMed database for articles published up to June 2018 using the terms "Mirizzi", "syndrome" and "cholangiocarcinoma". We identified 17 articles. The abstracts of the articles were evaluated, and only six of them involved cases of MS appearing as cholangiocarcinoma (Table 2).

Our case is similar to some of those in the literature, in which the correct diagnosis of MS was not made preoperatively (Table 2). The findings of (I) a scleroatrophic gallbladder, (II) fibrotic regions blocking the gallbladder and its ducts, and (III) negative results from the frozen section biopsy, led to the correct diagnosis. 
Table 2. Reported cases.

\begin{tabular}{|c|c|c|c|c|}
\hline Author & Age & $\begin{array}{c}\text { Ca 19-9 } \\
(\mathrm{U} / \mathrm{mL})\end{array}$ & $\begin{array}{l}\text { Image that suggested } \\
\text { cholangiocarcinoma }\end{array}$ & $\begin{array}{l}\text { Time of diagnosis } \\
\text { of MS }\end{array}$ \\
\hline Principe et al. 8 & - & 35.000 & ERCP & Intraoperatively \\
\hline Sanchez et al. 9 & - & - & - & Intraoperatively \\
\hline Khalid and Bhatti14 & 50 & - & Ultrasonography & Preoperatively \\
\hline Robertson 10 & 71 & 16.785 & CT scan, MRCP and ERCP & Intraoperatively \\
\hline Gibor et al. ${ }^{11}$ & 68 & 3.145 & CT scan, MRCP and ERCP & Postoperatively \\
\hline Gluskin and Komanduri28 & 72 & - & ERCP & Preoperatively \\
\hline
\end{tabular}

MRCP: magnetic resonance cholangiopancreatogram.

\section{Conclusion}

In summary, the rarity of MS and the lack of particular clinical features make it easy for it to be misdiagnosed as cholangiocarcinoma. This precise diagnosis was challenging since the disease mimicked the clinical presentation and images of a cholangiocarcinoma, even intraoperatively, and required anatomopathological study to confirm the diagnosis. Hence, despite the rarity of its incidence, physicians must keep in mind that MS can be a differential diagnosis for cholangiocarcinoma and vice versa.

\section{Conflicts of interest. None to declare. Source of funding. None.}

\section{References}

1. Kehr H. Die in meiner Klinik geübte Technik der Gallensteinoperationen mit einem Hinweis auf die Indikation und die Dauererfolge: auf Grund eigener, bei gesammelter Erfahrungen. München: J F Lehmann's Verlag; 1905.

2. Ruge E. Beiträge zur chirurgischen Anatomie der grossen Gallenwege (Ductus hepaticus, cysticus, choledochus und pancreaticus). Arch Klin Chir 1908; 87: 47-78.

3. Mirizzi PL. Sindrome Del Conducto Hepatico. J Int Chir 1948; 8: 73-77.

4. Abou-Saif A, Al-Kawas FH. Complications of gallstone disease: Mirizzi syndrome, cholecystocholedochal fistula, and gallstone ileus. Am J Gastroenterol 2002; 97: 249-254.

5. Csendes A, Diaz JC, Burdiles P, Maluenda F, Nava O. Mirizzi syndrome and cholecystobiliary fistula: a unifying classification. Br J Surg 1989; 76: 1139-1143.
6. Beltran MA. Mirizzi syndrome: history, current knowledge and proposal of a simplified classification. World J Gastroenterol 2012; 18: 4639-4650.

7. Beltran MA, Csendes A, Cruces KS. The relationship of Mirizzi syndrome and cholecystoenteric fistula: validation of a modified classification. World J Surg 2008; 32: 2237-2243.

8. Principe A, Del Gaudio M, Grazi GL, Paolucci U, Cavallari A. Mirizzi syndrome with cholecysto-choledocal fistula with a high CA19-9 level mimicking biliary malignancies: a case report. Hepatogastroenterology 2003; 50: 1259-1262.

9. Sanchez M, Gomes H, Marcus EN. Elevated CA 19-9 levels in a patient with Mirizzi syndrome: case report. South Med J 2006; 99: 160-163.

10. Robertson AG, Davidson BR. Mirizzi syndrome complicating an anomalous biliary tract: a novel cause of a hugely elevated CA199. Eur J Gastroenterol Hepatol 2007; 19: 167-169.

11. Gibor U, Perry ZH, Netz U, Glazer Y, Laufer L, Kirshtein B. CA 19-9 in the presence of obstructive jaundice due to Mirizzi syndrome. Isr Med Assoc J 2015; 17: 60-61.

12. Oladini O, Zangan SM, Navuluri R. Delayed Diagnosis of Mirizzi Syndrome. Semin Intervent Radiol 2016; 33: 332-336.

13. Antoniou SA, Antoniou GA, Makridis C. Laparoscopic treatment of Mirizzi syndrome: a systematic review. Surg Endosc 2010; 24: 33-39.

14. Khalid S, Bhatti AA. Mirizzi's syndrome: an interesting on table finding. J Ayub Med Coll Abbottabad 2014; 26: 621-624.

15. Lai EC, Lau WY. Mirizzi syndrome: history, present and future development. ANZ J Surg 2006; 76: 251-257.

16. Reverdito R, Moricz AD, Campos TD, Pacheco AMJ, Silva RA. Mirizzi syndrome grades III and IV: surgical treatment. Rev Col Bras Cir 2016; 43 (4): 243-247.

17. Erben Y, Benavente-Chenhalls LA, Donohue JM, Que FG, Kendrick ML, Reid-Lombardo KM, et al. Diagnosis and treatment of Mirizzi syndrome: 23-year Mayo Clinic experience. J Am Coll Surg 2011; 213 (1): 114-119; discussion 20-1. 
18. Chen H, Siwo EA, Khu M, Tian Y. Current trends in the management of Mirizzi Syndrome: A review of literature. Medicine (Baltimore) 2018; 97 (4): e9691.

19. Choi BW, Kim MJ, Chung JJ, Chung JB, Yoo HS, Lee JT. Radiologic findings of Mirizzi syndrome with emphasis on MRI. Yonsei Med J. 2000; 41 (1): 144-146.

20. Rayapudi K, Gholami P, Olyaee M. Mirizzi syndrome with endoscopic ultrasound image. Case Rep Gastroenterol 2013; 7 (2): 202-207.

21. Gómez MA, Meneses JC. Utilidad de la eco endoscopía en el síndrome de Mirizzi. Revista Colombiana de Gastroenterología 2010; 25: 312-315.

22. Pelaez-Luna M, Levy MJ, Arora AS, Baron TH, Rajan E. Mirizzi syndrome presenting as painless jaundice: a rare entity diagnosed by EUS. Gastrointestinal Endoscopy 2008; 67 (6): 974-975.

23. Witte CL. Choledochal obstruction by cystic duct stone. Mirizzi's syndrome. Am Surg 1984; 50: 241-243.
24. Aydin U, Yazici P, Ozsan I, Ersoz G, Ozutemiz O, Zeytunlu M, et al. Surgical management of Mirizzi syndrome. Turk J Gastroenterol 2008; 19: 258-263.

25. Safioleas M, Stamatakos M, Safioleas P, Smyrnis A, Revenas C, Safioleas C. Mirizzi Syndrome: an unexpected problem of cholelithiasis. Our experience with 27 cases. Int Semin Surg Oncol 2008; 5: 12.

26. Prasad TL, Kumar A, Sikora SS, Saxena R, Kapoor VK. Mirizzi syndrome and gallbladder cancer. J Hepatobiliary Pancreat Surg 2006; 13: 323-326.

27. Greer JP. Wintrobe's clinical hematology. Thirteenth edition. Philadelphia: Wolters Kluwer, Lippincott Williams \& Wilkins Health; 2014.

28. Gluskin AB, Komanduri S. Gastrointestinal: Mirizzi syndrome masquerading as primary cholangiocarcinoma. J Gastroenterol Hepatol 2018; 33: 335. 